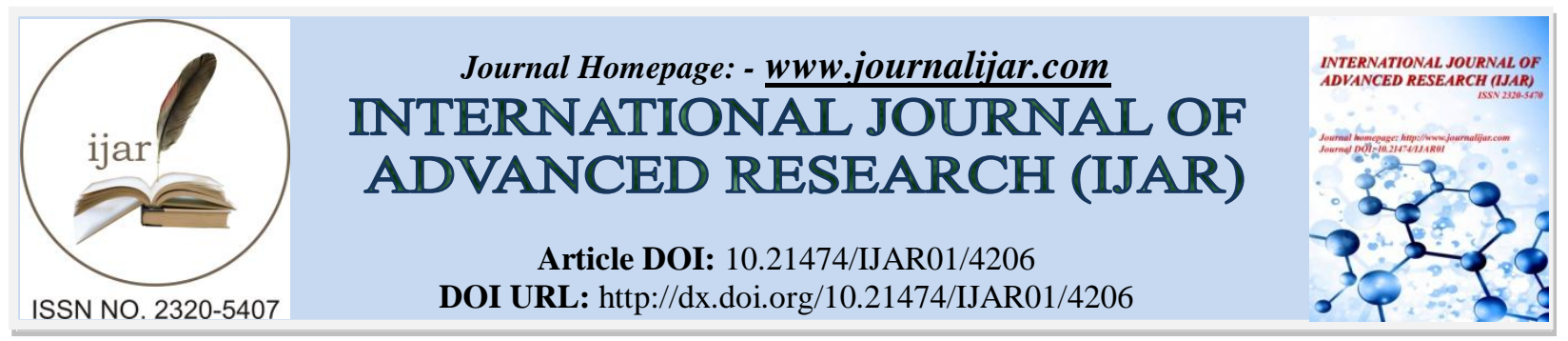

RESEARCH ARTICLE

\title{
FOLIAR REGENERATION IN CENTELLA ASIATICA (L.) URBAN (APIACEAE): AN IMPORTANT THREATENED MEDICINAL HERB.
}

\section{Deepa Palengara.}

Department of Botany, KAHM Unity Women's College, Manjeri, Malappuram, Kerala, India - 676122.

\section{Manuscript Info}

Manuscript History

Received: 17 March 2017

Final Accepted: 15 April 2017

Published: May 2017

Key words:-

Centella asiatica, regeneration, callogenesis, shoot multiplication, tryptophan.

\section{Abstract}

A tissue culture protocol for mass propagation of Centella asiatica from leaves was worked out. Better callus induction was observed from the young pale green leaves on MS medium supplemented with $1 \mathrm{mg} / \mathrm{l}$ 2,4-D, 0.5mg/l KIN and 4mg/l TRY. Calli were non-embryogenic, granular and friable. No callus induction was observed on MS medium without hormones. Maximum shoot regeneration from callus was observed on MS medium supplemented with $1 \mathrm{mg} / \mathrm{l} \mathrm{KIN} \mathrm{and} 0.1 \mathrm{mg} / \mathrm{l}$ BAP while the supply of NAA and BAP reduced the regeneration of multiple shoots. Present study prospects the in vitro conservation of $C$. asiatica and provides a novel source for the extraction of medicinally important secondary metabolites.

Copy Right, IJAR, 2017,. All rights reserved.

\section{Abbreviations:- \\ BAP: 6-Benzylaminopurine \\ NAA: 1-Naphthaleneacetic acid \\ 2,4-D: 2,4-Dichlorophenoxyacetic acid \\ KIN: Kinetin \\ TRY: Tryptophan}

\section{Introduction:-}

Centella is a diverse genus encompassing approximately 50 species which include the medicinally eminent plant Centella asiatica (L.) Urban (James and Dubery, 2009). The plant is otherwise called Indian pennywort and belongs to Apiaceae family. It is a stonoliferous, perennial, slightly aromatic herb flourishes plentifully in moist localities and distributed all over the world including India, China, Nepal, Madagascar, Srilanka, Indonesia and Southern America (Schaneberg et al., 2003).

Traditionally, the plant is used as nervine tonic and for the treatment of asthma, hypertension, bronchitis, dropsy, skin diseases and urethritis. The most eminent bioactive components present in C. asiatica are triterpenoid glycosides, saponin glycosides, indocentelloside, brahmoside, brahminoside, asiaticoside, theankuniside and flavonoids which are known to possess antileprotic, antifilarial, antibacterial, adaptogenic, antifeedant and antiviral properties (Warrier et al., 1994; Aziz et al., 2007; James and Dubery, 2009). Extract of whole plant is reported to have anticancerous activity (Yu et al., 2006) and the methanol extract of aerial parts of the C. asiatica inhibits the growth of human uterine carcinoma, human gastric carcinoma and murine melanoma cells in vitro (Yoshida et al., 2005). 
C. asiatica is a threatened medicinal herb and endemic to Western Ghats of South India (Nayar and Satry, 1987; Singh et al., 2015). Thus, it has become imperative to develop alternative approaches for its conservation, in order to protect it from the verge of extinction. In vitro culture technique offers a viable tool for the mass propagation of plant and the conservation of rare, threatened and endangered germplasm (Rao, 2004). Multiplication of $C$. asiatica through shoot tip, leaf and meristem culture has been reported (Tiwari et al., 2000; Nath and Buragohain, 2003; Martin, 2004; Mohapatra et al., 2008). This biotechnological approach helps to produce secondary metabolites and other bioactive compounds from the cultured tissues that avoid the use of natural plants for the extraction processes. The aim of the present study was to develop high frequency multiple shoots regeneration of $C$. asiatica from leaf explants utilizing the least number and various concentrations of plant growth regulators.

\section{Materials and methods:-}

Plant material: The young leaves of $C$. asiatica were collected from the campus of KAHM Unity Women's College, Manjeri, Malappuram, Kerala.

Surface sterilization of explant: The young leaves were first washed with running tap water for 15 minutes to remove the soil particles and other extraneous fine particles. Explants were soaked in 1\% Tween 20 for 10 minutes and washed thoroughly with running tap water. The explants were immersed in $0.5 \%$ bavistin for 1 hour and gently washed twice with tap water and double distilled water.

Callogenesis: To reduce the contamination of the MS medium at the time of transfer of the explants, all inoculation processes were carried out inside the laminar air flow chamber (LAF). Before starting the work, the culture flasks with growth medium, sterilized forceps and knife, spirit lamp, 70\% alcohol, sterile double distilled water and others needed for the inoculation process were surface sterilized using UV light for 30 minutes. The explants were sterilized using $0.1 \% \mathrm{HgCl}_{2}$ for 2-3 minutes, followed by washing with $70 \%$ alcohol for 3-5 minutes and sterile double distilled water for 5-6 times. The undesirable and dead portions of cut ends of the leaves were removed using the sterile knife. The leaf explants were placed horizontally in the culture flasks containing the media (MS+2,4D1mg/l+KIN0.5mg/l+TRY4mg/l, MS+2,4-D0.5mg/l+KIN1mg/l+TRY2mg/l, 2,4-D1mg/l+KIN0.5mg/l and 2,4$\mathrm{D} 0.5 \mathrm{mg} / \mathrm{l}+\mathrm{KIN} 1 \mathrm{mg} / \mathrm{l})$ with the help of sterile forceps and all the processes were done in front of the spirit lamp to keep a sterile ambience. The culture flasks were closed carefully and sealed with Klin film. Five replicas for each treatment were used for the present study. The cultures were maintained at $25 \pm 2{ }^{0} \mathrm{C}$, with a photoperiod of $8 \mathrm{~h}$ daylight and light intensity of $1500 \mu \mathrm{Em}^{-2} \mathrm{~S}^{-1}$.

Shoot multiplication: After four weeks, the callus was transferred to the shoot multiplication media (MS+KIN0.1 mg/l+BAP0.5mg/l, $\quad$ MS+KIN0.5mg/l+BAP0.3mg/l, $\quad$ MS+KIN1mg/l+BAP0.1mg/l, MS+BAP $1 \mathrm{mg} / \mathrm{l}+\mathrm{NAA} 0.5 \mathrm{mg} / \mathrm{l}$ and MS+BAP $0.5 \mathrm{mg} / \mathrm{l}+\mathrm{NAA} 1 \mathrm{mg} / \mathrm{l})$. The cultures were maintained at $25 \pm 2{ }^{\circ} \mathrm{C}$, with a photoperiod of $8 \mathrm{~h}$ daylight and light intensity of $1500 \mu \mathrm{Em}^{-2} \mathrm{~S}^{-1}$ for regeneration of multiple shoots.

\section{Results and discussion:-}

Plant tissue culture techniques for medicinal plants have been well established today which act as a powerful tool for germplasm conservation. Plant biotechnology comprises various cultural methods of plant organs which facilitate the experimental approaches for improvement of medicinal plants and crops.

Callogenesis: Callogenic shoot multiplication is a characteristic feature observed in micropropagation of $C$. asiatica (Bibi et al., 2011). Calli characteristics and induction response vary depending on explant source, explant size, media components and presence of plant growth regulator in media along with other culture conditions (Zia et al., 2007). In our study, leaf explants of $C$. asiatica developed callus at cut surfaces and subsequently covered the entire surface of explants within 21 days (Fig. 2A and 2B). Callogenesis was not observed in MS medium without growth hormones. Different concentrations of plant growth regulators including KIN and 2,4-D together with an aminoacid - Tryptophan were used to induce callogenesis from Centella leaves.

Calli formed in the study were non-embryogenic, granular and friable. At the initial stage, the calli were cream coloured which gradually turned to green within 28 days (Fig. 2C). Previous studies reported that MS medium supplemented with BA/KIN along with 2,4-D induced best callogenic response in Oryza seeds (Al-Khayri and Anderson, 1995). However our study revealed that non-embryogenic callus induction was better on MS medium supplemented with $2,4-\mathrm{D} 1 \mathrm{mg} / \mathrm{l}+\mathrm{KIN} 0.5 \mathrm{mg} / \mathrm{l}+\mathrm{TRY} 4 \mathrm{mg} / \mathrm{l}$ and $2,4-\mathrm{D} 0.5 \mathrm{mg} / \mathrm{l}+\mathrm{KIN} 1 \mathrm{mg} / \mathrm{l}+\mathrm{TRY} 2 \mathrm{mg} / \mathrm{l}$ compared to 
other growth regulator combinations. However, a fewer callogenic response was observed when explants grown on MS medium supplemented with 2,4-D $1 \mathrm{mg} / \mathrm{l}+\mathrm{KIN} 0.5 \mathrm{mg} / \mathrm{l}$ and $2,4-\mathrm{D} 0.5 \mathrm{mg} / \mathrm{l}+\mathrm{KIN} 1 \mathrm{mg} / \mathrm{l}$. The significant role of tryptophan on callogenesis is highlighted in our study which can be clarified by further biochemical studies.

Shoot multiplication: In the present study, callus induced from leaves were used to raise multiple clones of $C$. asiatica by supplying different concentrations of cytokinins including KIN and BAP. Within 14 days, callogenic response was enhanced in all KIN and BAP combinations used. Optimum callogenic response was observed in MS medium supplemented with $1 \mathrm{mg} / \mathrm{l} \mathrm{KIN}$ and $0.1 \mathrm{mg} / \mathrm{l} \mathrm{BAP}$ compared to other hormonal combinations (Fig. 2E), while minimum callus induction was on KIN0.1mg/l + BAP0.5mg/l. In the study, multiple shoots were initiated from the callus within 21 days. Among the hormonal combinations used, maximum number of multiple shoots $(8 \pm 2.6)$ was proliferated from the callus which was grown on MS medium supplemented with $1 \mathrm{mg} / \mathrm{l} \mathrm{KIN}$ and $0.1 \mathrm{mg} / \mathrm{l} \mathrm{BAP}$ (Fig. 1, Fig. 2E). In contrast, the number of multiple shoots was minima on KIN0.1mg/l + BAP0.5mg/l. Our study is in accordance with earlier studies on $C$. asiatica by Karthikeyan et al. (2009), that explains the positive role of KIN and BAP in shoot multiplication and callogenesis.

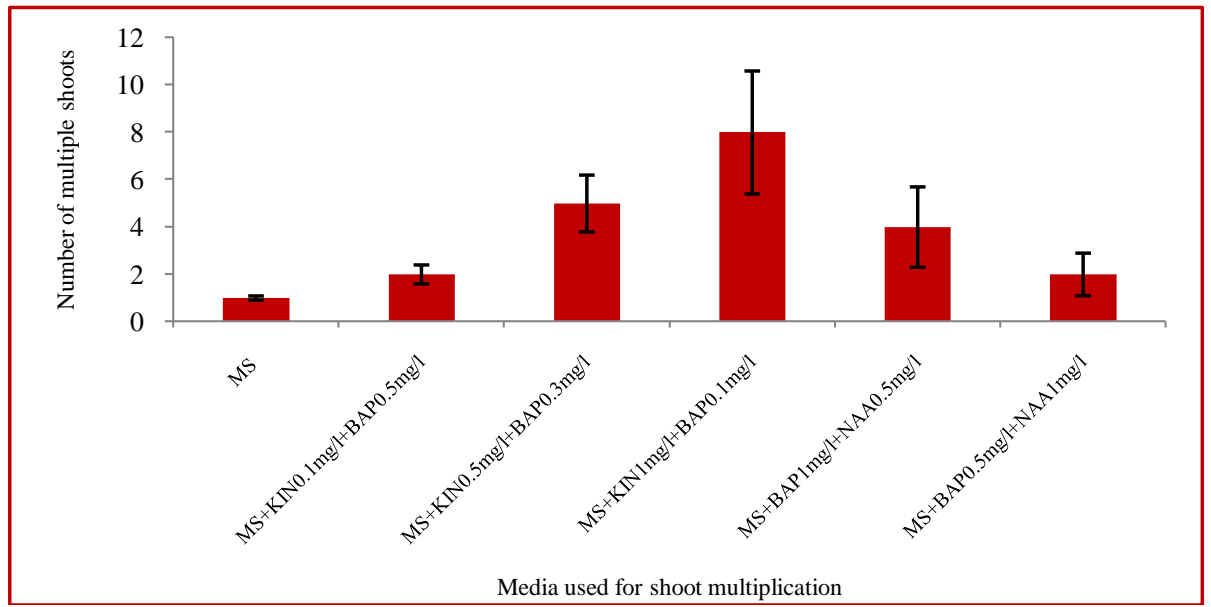

Fig.1:- Multiple shoot proliferation in in vitro C. asiatica on MS medium supplemented with different plant growth regulators within 28 days. The values are mean $\pm S E$ and $n=5$.

The combinations of BAP and NAA were also used to analyze their role on multiple shoot induction and callogenesis in $C$. asiatica. The study revealed that both callus and shoot induction was lesser on MS+BAP/NAA compared to the combinations of KIN and BAP used. Within 14 days undifferentiated cream coloured calli induction was enhanced followed by multiple shoot induction within 21 days. After 14 days the callus turned to green which was showed the indication of shoot regeneration. Here, best callogenesis and shoot regeneration were observed on MS medium supplemented with $1 \mathrm{mg} / \mathrm{l} \mathrm{BAP}$ and $0.5 \mathrm{mg} / 1 \mathrm{NAA}$ (Fig. 2D) compared to MS medium with $0.5 \mathrm{mg} / \mathrm{l} \mathrm{BAP}$ and $1 \mathrm{mg} / \mathrm{l} \mathrm{NAA}$. The number of shoots regenerated from callus grown on $1 \mathrm{mg} / 1 \mathrm{BAP}$ and $0.5 \mathrm{mg} / \mathrm{l}$ NAA was $4 \pm 1.7$ within 28 days while that on MS medium supplemented with $0.5 \mathrm{mg} / \mathrm{l}$ BAP and $1 \mathrm{mg} / \mathrm{l} \mathrm{NAA}$ was 2 \pm 0.9 (Fig. 1). The result is supported by the absence of shoot multiplication on hormone free MS medium.

\section{Conclusion:-}

Our study provides a new protocol for the callogenic shoot proliferation from leaves within 8 weeks. MS medium supplemented with $1 \mathrm{mg} / \mathrm{l} \mathrm{KIN}$ and $0.1 \mathrm{mg} / \mathrm{l} \mathrm{BAP}$ induced optimum callogenic shoot proliferation that indicates the need of specific concentration of plant growth regulators in organogenesis. Enhancement of callus induction from the leaves by the supplementation of tryptophan together with 2,4-D and KIN provides a new experimental approach which reveals the positive role of tryptophan on non-embryogenic callus induction. Transfer of this callus to shoot multiplication medium will produce $C$. asiatica clones that in turn will help to extract medicinally important biocompounds without the harvesting of natural plants (Kim et al., 2004). Through tissue culture techniques, we can conserve this medicinally important threatened plant. 

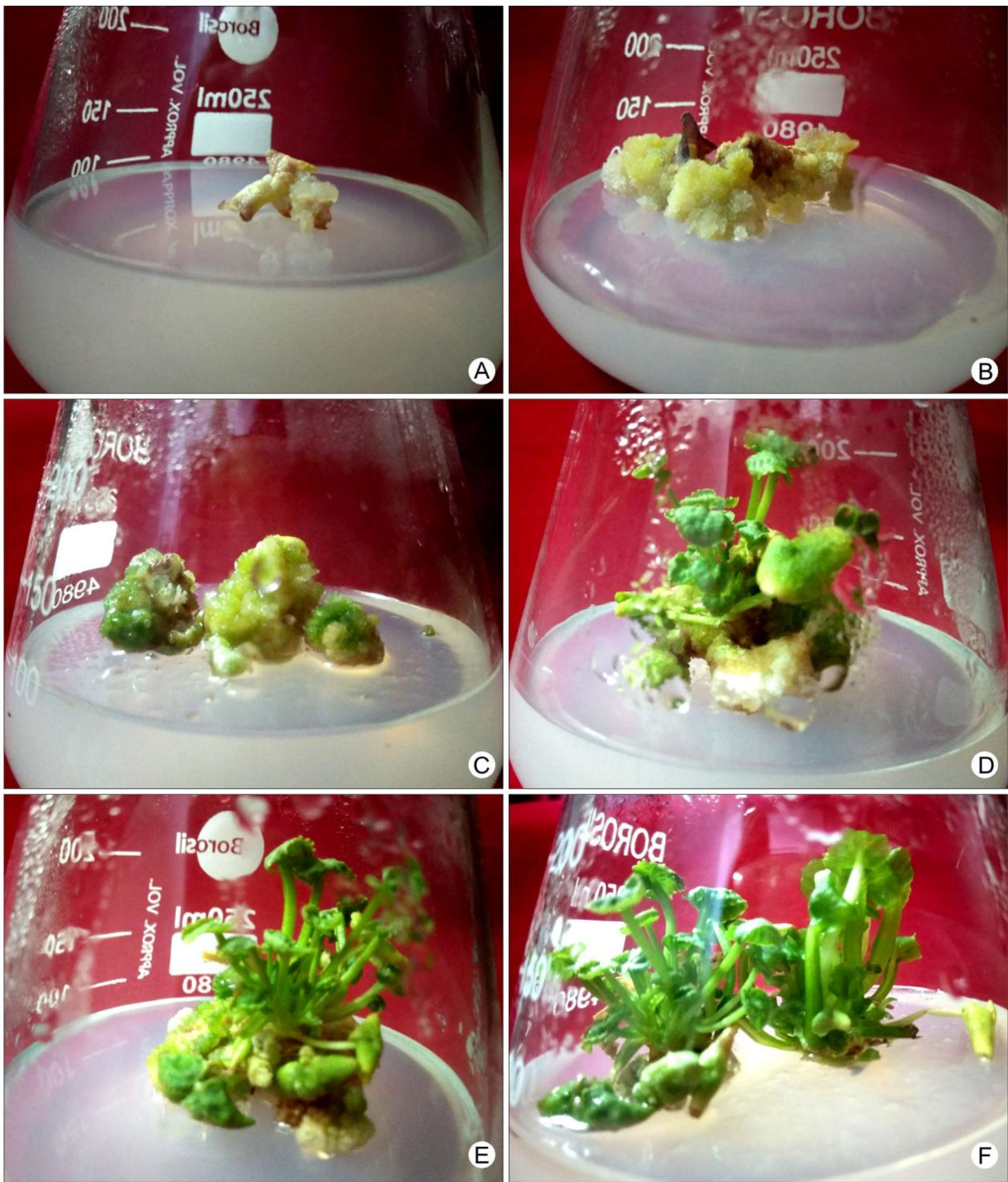

Fig. 2 A:- Callus induction from leaf of $C$. asiatica on MS medium supplemented with 2,4D1mg/l+KIN0.5mg/l+TRY4mg/l within 14 days, B. Callus induction from leaf of C. asiatica within 21 days, C. Callus induction from leaf of $C$. asiatica within 28 days, D. Shoot proliferation from foliar callus on MS medium supplemented with $1 \mathrm{mg} / 1 \mathrm{BAP}+0.5 \mathrm{mg} / \mathrm{l} \mathrm{NAA}$ within 21 days, E. Shoot proliferation from foliar callus on MS medium supplemented with $1 \mathrm{mg} / \mathrm{l} \mathrm{KIN}+0.1 \mathrm{mg} / \mathrm{l} \mathrm{BAP}$ within 21 days and $\mathbf{F}$. Multiple shoots on MS medium supplemented with $1 \mathrm{mg} / \mathrm{l} \mathrm{KIN}+0.1 \mathrm{mg} / \mathrm{l}$ BAP within 28 days. 


\section{References:-}

1. Aziz, Z. A., Davey, M. R., Power, J. B., Anthony, P., Smith, R. M., Lowe, K. C. (2007). Production of asiaticoside and madecassoside in Centella asiatica in vitro and in vivo. Biologia Plantarum, 51(1), 34-42.

2. Bibi, Y., Zia, M., Nisa, S., Habib, D., Waheed, A., Chaudhary, F. M. (2011). Regeneration of Centella asiatica plants from non-embryogenic cell lines and evaluation of antibacterial and antifungal properties of regenerated calli and plants. Journal of biological engineering, 5(1), 13.

3. Al-Khayri, J. M., Anderson, E. J. (1995). Callus Induction and Plant Regeneration of Commercial Rice (Oryza sativa L.), Cultivars. Proceedings Arkansas Academy of Science, 49.

4. James, J. T., Dubery, I. A. (2009). Pentacyclic triterpenoids from the medicinal herb, Centella asiatica (L.) Urban. Molecules, 14(10), 3922-3941.

5. Karthikeyan, K., Chandran, C., Kulothungan, S. (2009). Rapid clonal multiplication through in vitro axillary shoot proliferation of Centella asiatica L.

6. Kim, O. T., Kim, M. Y., Huh, S. M., Ahn, J. C., Seong, N. S., Hwang, B. (2004). Effect of growth regulators on asiaticoside production in whole plant cultures of Centella asiatica (L) urban. Journal of Plant Biology, 47(4), 361-365.

7. Martin, K. P. (2004). Plant regeneration through somatic embryogenesis in medicinally important Centella asiatica L., In Vitro Cellular and Developmental Biology-Plant, 40(6), 586-591.

8. Mohapatra, H., Barik, D. P., Rath, S. P. (2008). In vitro regeneration of medicinal plant Centella asiatica, Biologia Plantarum, 52(2), 339-342.

9. Murashige, T., Skoog, F. (1962). A revised medium for rapid growth and bio assays with tobacco tissue cultures, Physiologia plantarum, 15(3), 473-497.

10. Nath Tiwari, K., Chandra Sharma, N., Tiwari, V., Deo Singh, B. (2000). Micropropagation of Centella asiatica (L.), a valuable medicinal herb. Plant Cell, Tissue and Organ Culture, 63(3), 179-185.

11. Nath, S., Buragohain, A. K. (2003). In vitro method for propagation of Centella asiatica (L) Urban by shoot tip culture. Journal of Plant Biochemistry and Biotechnology, 12(2), 167-169.

12. Nayar, M. P., Satry, A. R. K. (1987). Red data book of Indian Plants. Botanical Survey of India, Howrah. 1(23).

13. Rao, N. K. (2004). Plant genetic resources: advancing conservation and use through biotechnology. African Journal of biotechnology, 3(2), 136-145.

14. Schaneberg, B. T., Mikell, J. R., Bedir, E., Khan, I. A., Nachname, V. (2003). An improved HPLC method for quantitative determination of six triterpenes in Centella asiatica extracts and commercial products. Die Pharmazie-An International Journal of Pharmaceutical Sciences, 58(6), 381-384.

15. Singh, G., Kaur, B., Sharma, N., Bano, A., Kumar, S., Dhaliwal, H. S., Sharma, V. (2015). In vitro micropropagation and cytomorphological evaluation of Centella asiatica (L.) Urban (mandukparni) from Himachal Pradesh, India-an endemic, endangered and threatened herb. Plant Tissue Culture and Biotechnology, 24(2), 155-171.

16. Warrier, P. K., Nambiar, V. P. K., Ramankutty, C. (1994). Indian Medicinal Plants. A Compendium of 500 species. Volume 1, Orien Longman Pvt. Ltd., Madras, India. 52-55.

17. Yoshida, M., Fuchigami, M., Nagao, T., Okabe, H., Matsunaga, K., Takata, Karube, Y., Fujioka, T. (2005). Antiproliferative constituents from Umbelliferae plants VII. Active triterpenes and rosmarinic acid from Centella asiatica. Biol. Pharm. Bull. 28, 173-175.

18. Yu, Q. L., Duan, H. Q., Takaishi, Y., Gao, W. Y. (2006). A novel triterpene from Centella asiatica. Molecules 11, 661-665.

19. Zia, M., Mannan, A., Chaudhary, M. F. (2007). Effect of growth regulators and amino acids on artemisinin production in the callus of Artemisia absinthium. Pakistan Journal of Botany (Pakistan). 